\title{
Uma análise original da fadiga no trabalho
}

LORIOL, Marc.

Le temps de la fatigue: la gestion sociale du mal-être au travail.

Paris: Anthropos, 2000. 293 p.

I ${ }^{1}$ Isabela Vieira |

${ }^{1}$ Psiquiatra, doutoranda em Saúde Coletiva, IMS-UERJ, Rio de Janeiro, Brasil. Endereço eletrônico: isabelamvieira@gmail.com

Fadiga, estresse, burnout. Termos cada vez mais presentes em nosso cotidiano, eles têm servido para caracterizar a vida contemporânea, sobretudo em seu aspecto de relação com o trabalho.

Fenômeno de crescente notoriedade, como demonstra a recente publicação de artigo em jornal brasileiro de grande circulação (URURAHY, 2012), o burnout pode ser visto, em certo sentido, como o protótipo de doença relacionada ao trabalho. Trata-se de um conceito elaborado na década de 1970 por psicólogos norte-americanos, e definido em termos de uma "queima" ou consumo total dos recursos energéticos individuais em função de um excesso de demandas (materiais e afetivas) do trabalho. Considerado uma consequência do estresse crônico, suas manifestaçōes principais seriam: a exaustão física e mental, a adoção de uma conduta distanciada e insensível em relação ao trabalho (o denominado "cinismo") e a sensação de ineficiência e baixa realização pessoal. A também chamada "síndrome do esgotamento profissional" foi inicialmente identificada em profissionais de saúde (principalmente enfermeiros) e assistência social - atividades ligadas ao contato humano e caracterizadas por altos níveis de idealização (com caráter de missão). No Brasil, o burnout faz parte da lista de doenças relacionadas ao trabalho, como uma dentre 12 categorias de transtornos mentais aí incluídas (BRASIL, 1999). 
É sobre esse "tempo da fadiga" que nos fala o sociólogo francês Marc Loriol, na obra em questão. Ao abordar as relaçôes entre fadiga e trabalho, o autor faz uma interseção entre os campos da Sociologia do Trabalho e da Saúde do Trabalhador (ST) - e sua subárea Saúde Mental e Trabalho (SMT). O livro, baseado em sua tese de doutorado, não possui, ainda, tradução para o português.

O pesquisador do Conseil National de la Recherche Scientifique (Universidade Paris 1-Sorbonne) trata da questão da fadiga no trabalho a partir de suas representações sociais em diferentes períodos históricos e por diferentes grupos sociais. Ele identifica, historicamente, uma distinção entre "boa" e "má" fadiga. A partir disso, investiga então a origem da noção de "má fadiga", propondo traçar seu percurso histórico e identificar de que maneira tal noção é utilizada como forma de regulação social de conflitos de trabalho. Estuda, portanto, a construção social e a difusão da noção de "má fadiga". Apoiando-se em um rico material oriundo de pesquisas de campo, analisa e compara a categoria dos enfermeiros (com o conceito de burnout) à dos operários, assistentes sociais, caminhoneiros e motoristas de ônibus. Entre as ideias principais, está a de que a qualificação da fadiga depende dos sentidos atribuídos ao trabalho, e é nesta medida que se pode falar da fadiga não apenas como um fenômeno individual (corporal, orgânico), mas sim como fenômeno social.

O livro está dividido em: introdução, quatro capítulos, conclusão e anexos. Ainda na introdução, cabe destacar a opção pelo estudo da fadiga "relacionada ao trabalho". Para o autor, a importância da questão da fadiga, sobretudo aquela que resulta do trabalho, deve-se ao fato de que ela:

[...] testemunha uma dimensão importante da vida social das sociedades industriais e pós-industriais, já que exprime, de alguma forma, os fundamentos corporais e psíquicos da ação humana e mais particularmente os limites das capacidades e da motivação do homem enquanto produtor. (p. 3, tradução e grifos nossos).

Daí o interesse científico de compreender o funcionamento da "máquina humana”, para poder conhecer o limiar de rendimento (além do qual se produziria doença, e uma indesejável perda de desempenho).

No primeiro capítulo, intitulado La sociogenèse historique de la notion de mauvaise fatigue, Loriol propõe uma "sociologia histórica" dos discursos sobre a fadiga: a tentativa é identificar/distinguir, na história desses discursos, algumas grandes formas cuja difusão nas diferentes sociedades pode ser compreendida no contexto da evolução das estruturas sociais. 
Basicamente, teria havido uma transição da noção de desgaste para a de má fadiga. Assim, na Antiguidade, predominava a noção de "desgaste" como algo inevitável, parte da vida, advindo do trabalho de forma natural: o ser humano, a partir do nascimento, vai se desgastando até morrer. A partir do surgimento das figuras da acédia (século VI), da melancolia (século XVI), da neurastenia (século XIX) e, após a década de 1970, com a descrição de duas novas entidades clínicas - o burnout (de viés teórico mais psicológico) e a síndrome da fadiga crônica (cujo fundamento é orgânico) -, é que se desenvolve historicamente a noção de "má fadiga": aquela subjetiva, produzida pelo esforço intelectual e/ou pela vida urbana. Em oposição à "boa" fadiga - que advém de atividades livremente escolhidas, em harmonia com a natureza e a natureza humana -, a fadiga "ruim" não desaparece com o repouso (é crônica), resulta de atividades ou modos de vida contrários à "natureza humana" (tem caráter coercitivo) e só é suprimida pelo retorno a uma vida mais saudável ou pelo apelo a um profissional (de saúde, no caso).

É possível identificar, em cada forma discursiva, elementos "novos" que, ao longo do tempo, vão resultar no conceito abrangente de "má fadiga". Assim, no caso da acédia dos monges (definida como um estado de apatia e tristeza associado à falta de fé), há a experiência social nova do eremita, sozinho perante Deus e a própria consciência, como uma das primeiras manifestações de individualismo. $\mathrm{Na}$ melancolia, inovações teóricas como a noção de "espírito vital” (cujo desperdício levaria à fadiga), a ênfase em seu fundamento orgânico e a ideia de doença como "independente da vontade", abrindo espaço para a medicalização da fadiga intelectual. A "medicina dos nervos" do século XVIII, com suas noções de feixes de fibras por onde circula a energia nervosa, irá embasar o conceito de neurastenia. $\mathrm{O}$ mecanismo fisiológico baseado na ideia de agressão externa (viral), na síndrome de fadiga crônica; e o "esgotamento energético" na síndrome de burnout.

Em todos estes casos, a ideia de uma falta de força, de uma fadiga sem ligação com o trabalho físico, se desenvolve progressivamente no contexto de um processo de racionalização e de coerção - o processo civilizador. $\mathrm{O}$ indivíduo deve se dobrar a novas regras e aceitar novas interdependências. A necessidade crescente de um autocontrole do indivíduo e uma nova percepção social do tempo constituem duas faces importantes desse processo, favorecendo o desenvolvimento dos discursos sobre a fadiga. O controle social pela doença, cujo objetivo é mais 
normalizar (conformar à norma) do que excluir, é tão mais eficaz quanto mais internalizado. O saber médico, por sua vez, torna-se o instrumento através do qual o autocontrole se realiza. Quanto à nova percepção social do tempo, a passagem do tempo "polícrono" para o "monócrono", ocorrida pela primeira vez nos monastérios, traz consigo a divisão trabalho-lazer e a sensação de frustração e angústia de não conseguir cumprir as tarefas previstas a tempo, constituindo, assim, a origem do sentimento de "estresse" (fadiga como "patologia do tempo").

O capítulo 2 (La difficile reconnaissance de la mauvaise fatigue des ouvriers) mostra como a fadiga operária é percebida como desgaste (fadiga física), pelos próprios operários e pelos médicos. Loriol estrutura sua análise em três eixos: o discurso médico-científico, o discurso sindicalista e o discurso dos operários.

Historicamente, é apenas no século XIX que a fadiga dos operários se torna objeto de preocupação, na medida em que o poder público, os empregadores e a burguesia se dão conta da importância do fator humano na produção industrial. Mas o interesse se restringe a aumentar a produtividade, a uma melhor adaptação à mecanização e à racionalização da produção. É a reboque deste interesse na produtividade que uma literatura científica sobre a fadiga ligada ao trabalho industrial vai crescer consideravelmente a partir de 1880 (e em especial na década de 1950, após a Segunda Guerra). No item De la psychophysiologie de la fatigue à la psychopatologie du travail, o autor retraça a história do campo de estudos das relações saúde-trabalho. Cabe observar, a partir desta descrição histórica dos discursos científicos sobre a fadiga operária, o quanto a questão da fadiga é central para a constituição do campo da ST (e particularmente da SMT): é ela que estrutura o próprio campo.

Apesar de abrir espaço para o reconhecimento da fadiga dos operários, com as noções de unicidade da fadiga, isto é, a indissociabilidade de seus componentes muscular e mental (proveniente da teoria psicofisiológica), e de carga mental (dos estudos em psicopatologia do trabalho), essas teorias não foram capazes de sustentar tal reconhecimento, sob críticas de fragilidade metodológica. A razão para isso, segundo o autor, é uma resistência social em reconhecer o malestar subjetivo dos "pobres" em relação aos "ricos". Ele argumenta que os frágeis fundamentos das teorias sobre neurastenia não impediram sua aceitação como explicação viável da fadiga dos ricos, enquanto que no caso dos operários, não foi possível fazer reconhecer a validade dos estudos, a não ser por uma recusa 
esterilizante à subjetividade: “Ou seja, é sobre o 'terreno social' - e não o científico - que devem ser buscadas as razões da difusão da ideia de má fadiga nos meios sociais mais amplos." (p. 80).

$\mathrm{Na}$ construção e difusão da noção de fadiga relacionada ao trabalho, Loriol aponta o papel de "empreendedores morais" assumido pelos sindicatos franceses. A forma dos discursos sobre a fadiga, entretanto, varia em função do projeto político e social de cada central sindical: assim, para a Confederação Geral do Trabalho (CGT), a fadiga e o estresse se explicam, dentro da teoria marxista, pela vontade dos capitalistas de explorar intensivamente a força de trabalho para aumentar a mais-valia; para a Força Operária (FO), o tema da fadiga e do estresse é ocasião de sublinhar a possível convergência de interesse entre assalariados e empresários; e para a Confederação Francesa Democrática do Trabalho (CFDT), o foco é a necessidade de os trabalhadores tomarem nas mãos a própria saúde, no nível da implementação dos Comitês de Higiene, Saúde e Condições de Trabalho (CHSCT).

Em relação aos discursos operários individuais, observa-se certa reticência em falar da própria fadiga, sendo suas representações mais ligadas à noção de desgaste, indissociáveis das representações de velhice e de aposentadoria como direito social ao descanso. $\mathrm{O}$ desgaste, contrariamente à fadiga cotidiana, ofereceria a vantagem de não ser a marca de uma fraqueza pessoal. Tais observações provêm de vários estudos sobre os sentidos do trabalho para diferentes classes de trabalhadores (dos quais são extraídas inúmeras falas). Embora a forma típica de discurso dos trabalhadores seja a do desgaste, são encontradas também referências à fadiga enquanto monotonia, tédio e estresse. Em geral, tais representações estão presentes nos discursos de trabalhadores mais qualificados. Nesses relatos, a noção de estresse, por exemplo, aparece como bem distinta da noção de fadiga: o "estresse" é mental; a "fadiga" é física.

O terceiro capítulo (De la fatigue des infirmières au burn out) aborda a fadiga dos enfermeiros. Em comparação ao trabalho operário, a atividade de enfermagem comporta uma especificidade, por ter como objeto o ser humano. Às profissões de saúde está destinada socialmente a tarefa de lidar com o sofrimento, a doença e a morte - endereçamento ligado ao processo civilizador. Para dar conta desta tarefa, o profissional deve desenvolver distanciamento e autocontrole, que visam a preservar a própria integridade psíquica, ao mesmo tempo em que garantem 
maior eficácia terapêutica. Este difícil equilíbrio é representado nas queixas de fadiga dessa categoria profissional. A partir da análise dos discursos dos enfermeiros sobre a fadiga, o autor tenta desvelar as funções latentes de regulação social por meio das quais tais discursos atuam.

Quanto às representaçôes dos enfermeiros sobre a própria fadiga, destacamse algumas formas típicas: a frequente distinção entre fadiga física e mental (e o uso da fadiga física para prevenir a fadiga mental); a ideia de desgaste acelerado da profissão (a "vida útil" de uma enfermeira é percebida como curta); e a centralidade da relação cuidador-paciente como determinante da distinção entre boa e má fadiga - nem sempre coincidindo com a distinção entre fadiga física e mental: uma fadiga física pode também ser julgada como "má” se resulta de um esforço físico ligado a um trabalho relacional percebido como pouco satisfatório.

Loriol identifica o recurso a medicalização/psicologização como parte de uma estratégia para lidar com o sofrimento derivado da relação cuidador-paciente, considerada pelos entrevistados a fonte específica da fadiga da enfermagem. Esta medicalização é direta (uso de vitaminas, ansiolíticos, estimulantes; licenças médicas; busca pela escuta médica ou psicológica) e indireta (quando utilizada como um meio para a elaboração coletiva de transformação das coerçôes profissionais em fontes potenciais de prazer no trabalho). A medicalização indireta inclui um trabalho de reconstrução simbólica do paciente, possível apenas por intermédio dos profissionais psicólogos.

Outra estratégia éa busca pela "profissionalização" da atividade de enfermagem. A construção da identidade profissional se dá através do estabelecimento de seu "papel específico" (rôle propre): em oposição ao do médico, e diferenciado em relação ao do auxiliar de enfermagem. A técnica torna-se a arma para as emoções negativas (na base do sentimento de má fadiga): a enfermeira que domina suas emoções é mais profissional. Para atingir o autocontrole emocional, a meta deve ser manter a separação entre "eu pessoal" e "eu profissional", e a gestão do estresse, a estratégia preferencial de autorregulação profissional.

Nesse contexto, o sucesso da teoria psicológica do burnout pode ser compreendido por sua capacidade de oferecer uma resposta (ao menos teórica) às contradições e aos problemas ligados tanto à relação com os doentes quanto à posição da enfermeira dentre os demais profissionais de saúde. O burnout indica, em negativo, a "boa" distância entre o super- e o subinvestimento 
afetivo (a exaustão e o cinismo) - embora, na prática, tal distância seja muito estreita, talvez mítica. Outra vantagem desta teoria se deve a sua capacidade de formalizar, através de testes, a subjetividade dos enfermeiros e a perspectiva de análise individualizante da psicologia. De fato, a existência de um instrumento de aferição de burnout (o Maslach Burnout Inventory, ou MBI) contribuiu para a efetiva construção do esgotamento profissional. Ao produzir uma objetivação das queixas subjetivas, através de sua representação em uma escala, promover-se-ia uma suposta equivalência entre o resultado positivo no teste e a presença "real" do burnout (o que é analisado criticamente pelo autor).

Diferentemente dos operários, observa-se, entre os enfermeiros, uma recusa às açôes sindicais, o que traduziria uma tendência à individualização da gestão dos problemas de fadiga. Uma breve comparação também é feita com os profissionais de serviço social. Ao contrário dos enfermeiros, os assistentes sociais entrevistados apontaram mais as condições macrossociais e organizacionais (crise econômica, burocracia, políticas públicas) do que os fatores individuais como principal fonte de sofrimento psíquico, ao provocarem uma situação de "dupla coerção" (falta de condições materiais para atender a demanda associada à dificuldade de mudar a condição dos que buscam seus serviços). Em comum, no entanto, está a questão da profissionalização: a necessidade de racionalizar/ tecnicizar o cuidado e fundar um corpo de conhecimentos capaz de guiar a ação e liberar o profissional das coerções.

No quarto capítulo (Mauvaise fatigue et régulation des conflits au travail), o autor se utiliza da noção de "compromisso social" (compreendida em sua dimensão de ajustar valores e visões de mundo para tornar compatíveis exigências e representações muitas vezes contraditórias), para analisar as formas de regulação de conflitos no trabalho intermediadas pelos discursos sobre a fadiga. No caso do burnout da enfermagem, as ideias sobre estresse/fadiga - ambíguas e flexíveis - serviram bem a este propósito, ao permitir a formação de um compromisso implícito entre as enfermeiras (em busca de reconhecimento), a hierarquia da enfermagem (às voltas com a questão da profissionalização) e a direção hospitalar (com seus objetivos de gestão).

Loriol descreve como se deu esse processo na França, a partir das negociações em torno das reivindicações dos enfermeiros e da subsequente resposta do poder público e das direções hospitalares, no que se configurou como a "questão da 
enfermagem", no final dos anos 1980. As propostas incluíram: revalorização da profissão; realização de pesquisas sobre cargas de trabalho; e adoção de técnicas de gestão de estresse. Os atores discordantes (médicos do trabalho e sindicatos) perdem espaço; suas críticas (de que os estudos de carga de trabalho visariam apenas à economia de pessoal), associadas à desconfiança dirigida aos sindicalistas, não são apoiadas pelos enfermeiros.

Além disso, a lógica de gestão favoreceu a emergência de novos atores - os psicólogos -, cujo discurso voltado para o indivíduo é mais compatível com os interesses da instituição hospitalar. O autor dá outros exemplos da dinâmica desse compromisso social em torno da questão da fadiga, nos casos dos caminhoneiros e dos motoristas de ônibus. Estes últimos teriam um modelo de estresse/fadiga mais próximo ao da "má fadiga" do que os primeiros.

Finaliza o capítulo uma interessante discussão a respeito da emergência da satisfação pessoal como "nova moral". A transformação histórica do valor social atribuído ao trabalho é o eixo da argumentação. De dever social (desde o século XVIII), em nossos dias, o trabalho passa a ser visto cada vez mais como fonte de satisfação pessoal. Dessa forma, a relação homem-sociedade se inverte: agora é a sociedade que tem de fornecer um ambiente favorável à satisfação individual. O sentido dado ao trabalho - se dever social ou fator de satisfação pessoal vai modificar também a expressão das queixas de fadiga em termos de saúde física (no primeiro caso) ou "saúde moral" (no segundo), conforme exemplifica a partir de trechos de entrevistas com trabalhadores. A visão do trabalho como fonte de satisfação pessoal estaria ligada também a um discurso gerencial. Loriol aventa dois fatores para explicar a difusão da ideologia gerencial: o aumento do narcisismo (com sua busca pela realização pessoal), ligado, por sua vez, ao declínio dos "grandes sistemas de sentido" (religião e política); e a assunção deste lugar de sentido pela empresa, que tentaria canalizar para si uma parte da motivação pessoal dos funcionários, colocando-se como um meio para realização pessoal através dos objetivos da empresa.

Neste ponto, vale lembrar que a questão do narcisismo tem sido apontada por outros autores do campo das ciências sociais que se debruçaram sobre o tema burnout. Em estudo etnográfico com trabalhadores suecos encaminhados a centros de reabilitação profissional em função do diagnóstico de burnout, Friberg (2006) conclui pela presença de uma espécie de "narcisismo moral": este teria não 
um caráter patológico, mas sim de dever moral. Para se proteger do burnout, seria imperativo aprender a "cuidar de si mesmo" em primeiro lugar. Esta necessidade estaria ligada a um aumento do narcisismo na sociedade sueca em geral, em um contexto de transformações sociais e econômicas recentes.

Na conclusão, Loriol alerta sobre a necessidade de uma "sociologia da fadiga" de romper com as ideias de energia e de carga mental: a metáfora energética. Em vez disso, o objetivo é mostrar que o sentimento de fadiga depende do sentido que reveste a ação. $\mathrm{O}$ pesquisador critica alguns autores em sociologia (dentre os quais Alain Ehrenberg) que teriam caído no equívoco de tomar a metáfora energética pela realidade, ao falar em "custos" - em termos de dispêndio de energia/força - induzidos pela adaptação ao mundo moderno. Argumenta que um trabalho mental, reflexivo, não necessariamente leva à fadiga: ele pode ser fonte de motivação.

Então, não é na maior liberdade e na obrigação de escolha ou de imaginação daí decorrente que se devem procurar as causas de nossa fadiga, mas sim naqueles esforços que não são sustentados por modelos sociais claros e evidentes, cujo sentido apresenta problema (p. 254, tradução nossa).

O livro traz ainda uma seção de anexos, contendo informação mais detalhada sobre os questionários semiestruturados utilizados pelas diferentes equipes de pesquisa que compõem o grupo coordenado pelo autor.

A densa obra de Loriol enriquece o campo da sociologia, ao abordar de maneira original o tema da fadiga; ao mesmo tempo, fornece valiosa contribuição às áreas da saúde dedicadas ao estudo das relações saúde-doença-sofrimento e trabalho, ao contextualizá-las histórica e socialmente. Além disso, a abordagem sociológica (e antropológica), pela via do estudo das representações e da construção de identidade, aproxima-se, em especial, das perspectivas "psi”, interessadas em questôes da subjetividade. Em especial, a escolha pelo enfoque de Elias - com sua noção de processo civilizador - traz uma vantagem adicional, pois permite ultrapassar a dicotomia indivíduo-sociedade que "assola" o campo de estudos sobre burnout: recai-se invariavelmente no problema de entendê-lo ou como fenômeno individual (de responsabilidade, portanto, do indivíduo) - caso das teorias psicológicas; ou como fenômeno social (se a causa é a organização do trabalho, não se trata de um problema “de saúde" verdadeiramente) - o que muitas vezes impede seu reconhecimento em instâncias como a perícia previdenciária, por exemplo. 
Assim, a leitura dessa obra nos dá elementos para refletir criticamente sobre a forma específica como emerge o conceito de burnout em nossa sociedade, quando nos deparamos com um artigo de jornal como o citado ao início desta resenha - que considera estresse/burnout importante por oferecer risco à produtividade: podemos ver que, ainda hoje, do mesmo modo como no século XIX, o interesse e o próprio conhecimento no tema são guiados, em grande medida, pela questão da produtividade.

\section{Referências}

BRASIL. Ministério da Saúde. Portaria MS no 1.339, de 18 de novembro de 1999. Lista de doenças relacionadas ao trabalho. Diário Oficial da Uniāo, Brasília, DF, 19. nov. 1999. Seção I, p. 21-29.

FRIBERG, T. Diagnosing burn-out: an anthropological study of a social concept in Sweden. Lund: Media-Tryck, 2006. 193 p.

LORIOL, M. Le temps de la fatigue: la gestion sociale du mal-être au travail. Paris: Anthropos, 2000. 293 p.

URURAHY, G. Executivos no limite, risco para os negócios. O Globo, Rio de Janeiro, 18. out. 2012. Primeiro caderno, p. 21. 